\title{
Kyviskes Calibration Baseline: measurements and improvements analysis
}

\author{
Arunas Buga ${ }^{\mathrm{a}}$, Raimundas Putrimas ${ }^{\mathrm{a}}$, Dominykas Slikas ${ }^{\mathrm{a}}$, Jorma Jokela ${ }^{\mathrm{b}}$ \\ ${ }^{a}$ Institute of Geodesy, Vilnius Gediminas Technical University, Sauletekio al. 11, Vilnius 10223, Lithuania \\ ${ }^{b}$ Finnish Geodetic Institute, Geodeetinrinne 2, FI-02430 Masala, Finland
}

\begin{abstract}
Kyviskes Calibration Baseline is the longest calibration baseline in the Lithuania. Kyviskes Calibration Baseline was established by the Institute of Geodesy, VGTU in 1996 for the calibration of EDM instruments. Finnish Geodetic Institute together with Institute of Geodesy, VGTU are measuring Kyviskes Calibration Baseline regularly. The same Kern Mekometer ME5000 EDM instrument was used for all measurements performed. The Kyviskes baseline was converted to a triangle-shaped test field in year 2000, and three cycles of remeasurements were made in 2001, 2007 and 2008. Analysis of baseline calibration results of the baseline is performed and presented. The results of the baseline length are air temperature correlated. Possible reason for this are analyzed. Kyviskes Calibration Baseline became a test field for the different purposes after building seventh observation pillar. Kyviskes Calibration Baseline is the length standard for Lithuania and is used by Calibration laboratory regularly. The results confirm the good stability of the baseline, which is now used for calibration of EDM instruments and testing of total stations and GNSS measurement equipment.
\end{abstract}

Keywords: Calibration; EDM; baseline.

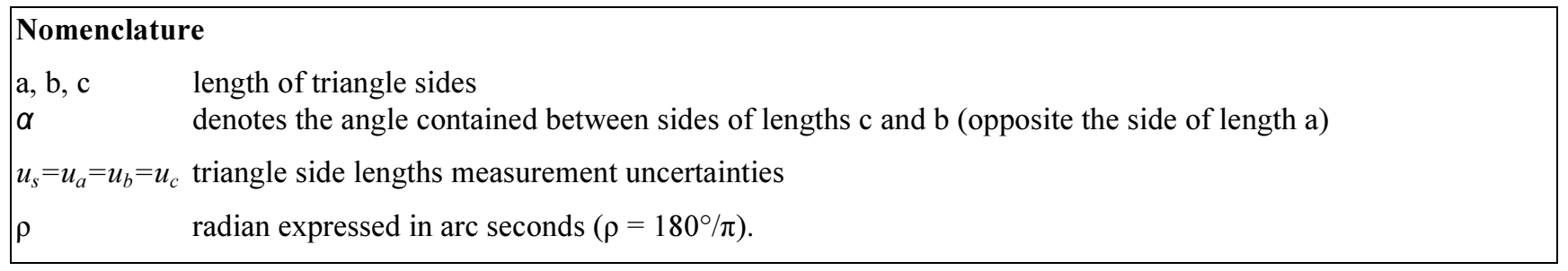

\section{Introduction. Kyviskes Calibration Baseline}

Kyviskes Calibration Baseline is the longest (1320 metres) calibration baseline in the Lithuania and among few most often calibrated in the Europe lately. It is located in the local airfield $15 \mathrm{~km}$ from Vilnius. Kyviskes Calibration Baseline was established by the Institute of Geodesy, VGTU in 1996 for the calibration of EDM instruments [1]. Finnish Geodetic Institute together with Institute of Geodesy, VGTU are measuring Kyviskes Calibration Baseline on a regular basis in 5-7 year cycles. The same Kern Mekometer ME5000 EDM instrument was used for all measurements performed. The Mekometer has been regularly calibrated at the Nummela Standard Baseline which is measured with the Väisälä white light interference comparator with total standard uncertainty of $\pm 0.09 \mathrm{~mm} / \mathrm{km}$ in the traceability chain to the definition of the metre.

Repeated high precision measurements with traceability to Finnish National Standard are essential in proving stability and reliability of Kyviskes Calibration Baseline. The baseline of the Finnish Geodetic Institute (FGI) at Nummela, Finland, has been well established for decades and is the reference for a number of high-precision baselines all over the world, including the newest in Austria, Estonia and Germany [2].

The extended uncertainty of the scale transfer to Kyviskes baseline never exceeded $\pm 0.9 \mathrm{~mm}$. The Kyviskes baseline was extended to a triangle-shaped test field in year 2000, and three cycles of re-measurements of newly created combination of baselines were made in 2001, 2007 and 2008 [3]. Analysis of calibration results of the baseline is performed and presented.

Corresponding author: Arunas Buga. E-mail address: arunas.buga@vgtu.lt

http://dx.doi.org/10.3846/enviro.2014.195

(C) 2014 The Authors. Published by VGTU Press. This is an open-access article distributed under the terms of the Creative Commons Attribution License, which permits unrestricted use, distribution, and reproduction in any medium, provided the original author and source are credited. 
Though obtain results prove high accuracy of the determined length of Kyviskes Calibration Baseline but we noticed the baseline lengths minor variations which are air temperature correlated. Possible reason for this is discussed below.

Kyviskes Calibration Baseline became a test field for the different purposes after building seventh observation pillar. Calibration laboratory of Institute of Geodesy, VGTU is accredited for EDM instruments calibration by Lithuanian National Accreditation Bureau since 2001. Laboratory fulfils LST EN ISO/IEC 17025:2005 standards. Kyviskes Calibration Baseline is the length standard for Lithuania and is used by Calibration laboratory regularly. The results confirm the good stability of the baseline, which is now used for calibration of EDM instruments and testing of total stations and GNSS measurement equipment. Some analysis of Kyviskes test field usage for angle calibration is analysed.

\section{Conversion from the calibration baseline to the test field}

The purpose of building Kyviskes Calibration Baseline was to create calibration facilities for EDM instruments. Suitable site was selected in Kyviskes airfield (established in 1947) which is still in use for pilots training). Kyviskes airfield was assigned to the VGTU in 2009. Flat unobstructed area of the airfield is very well fitting for the calibration baseline. Lately area of the airfield and Kyviškès Calibration Baseline were surrounded by metal net fence limiting possible access of strangers.

Six observation pillars were fundamented on the grassland on the western side of the airfield. Observation pillars are located in line from North to South. Distances from first to sixth pillar are $100 \mathrm{~m}, 360 \mathrm{~m}, 1120 \mathrm{~m}, 1300 \mathrm{~m}$ and $1320 \mathrm{~m} .10$ more calibration line combinations are possible from other than first pillar. Seventh pillar was built in the year 2000 on the eastern side of the runway, $644 \mathrm{~m}$ to $949 \mathrm{~m}$ from the other pillars. By building the seventh pillar additional 6 baselines in the test field were created. The triangle-shaped test field provides more possibilities for testing of surveying instruments [4, 5, 6]. Calibration of the Kyviškès Baseline is done on the regular basis at approximate 5 years interval.

With establishment of seventh pillar the idea was raised to use calibration baseline pillars for the calibration of theodolites and total stations. By extending calibration baseline to a triangle-shaped test field in 2000 the preconditions were created for the usage of baselines not only for EDM instrument calibration but also to test GPS receivers, theodolites and total stations. By building the 7th pillar a test field was created with 21 different possible baseline (Fig. 1).

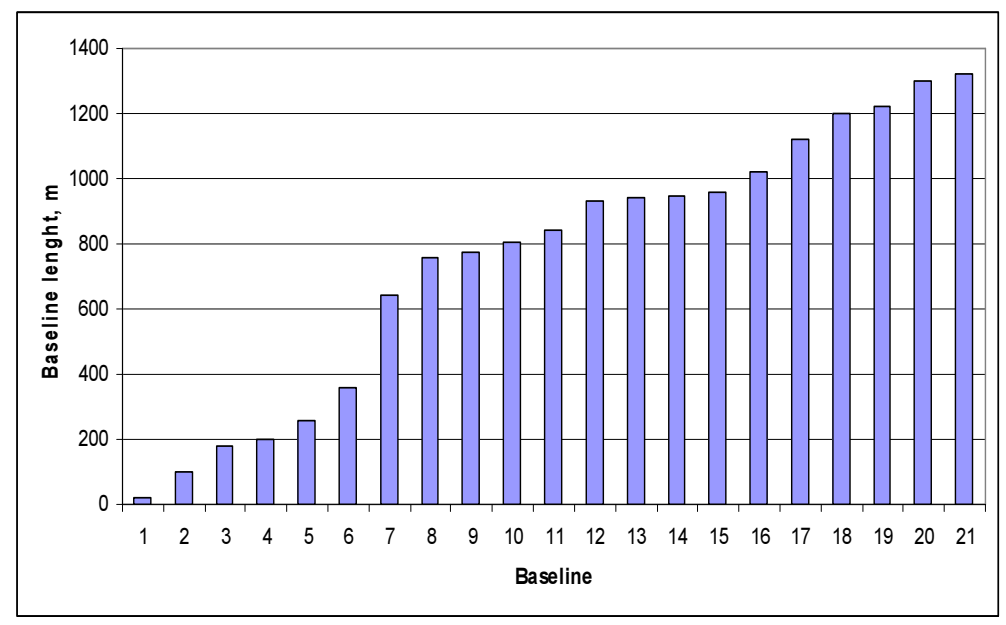

Fig. 1. Possible baseline combinations in Kyviskes test field

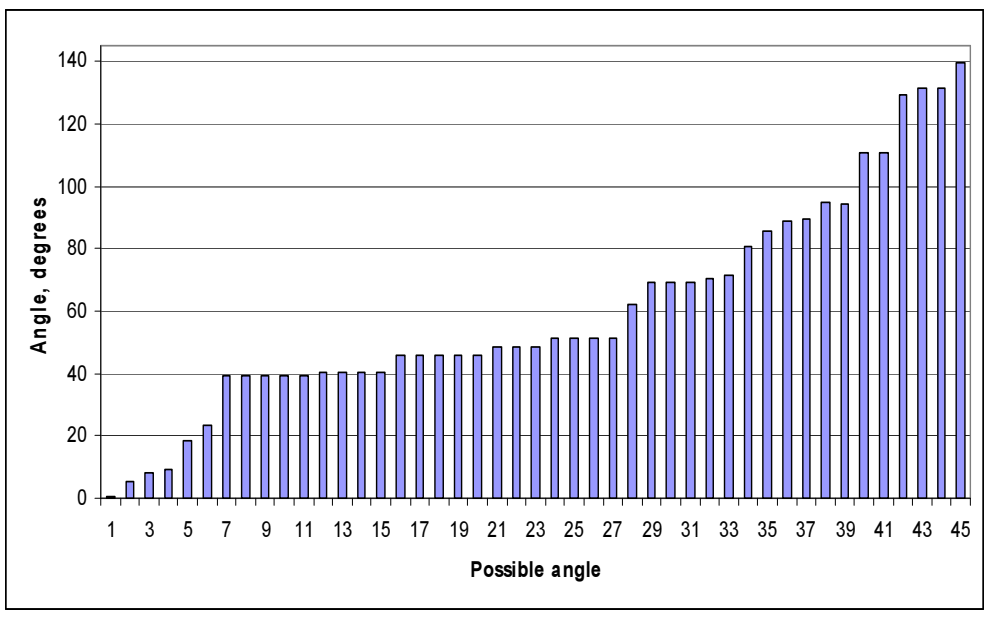

Fig. 2. Angle values in degrees at Kyviskes test field 


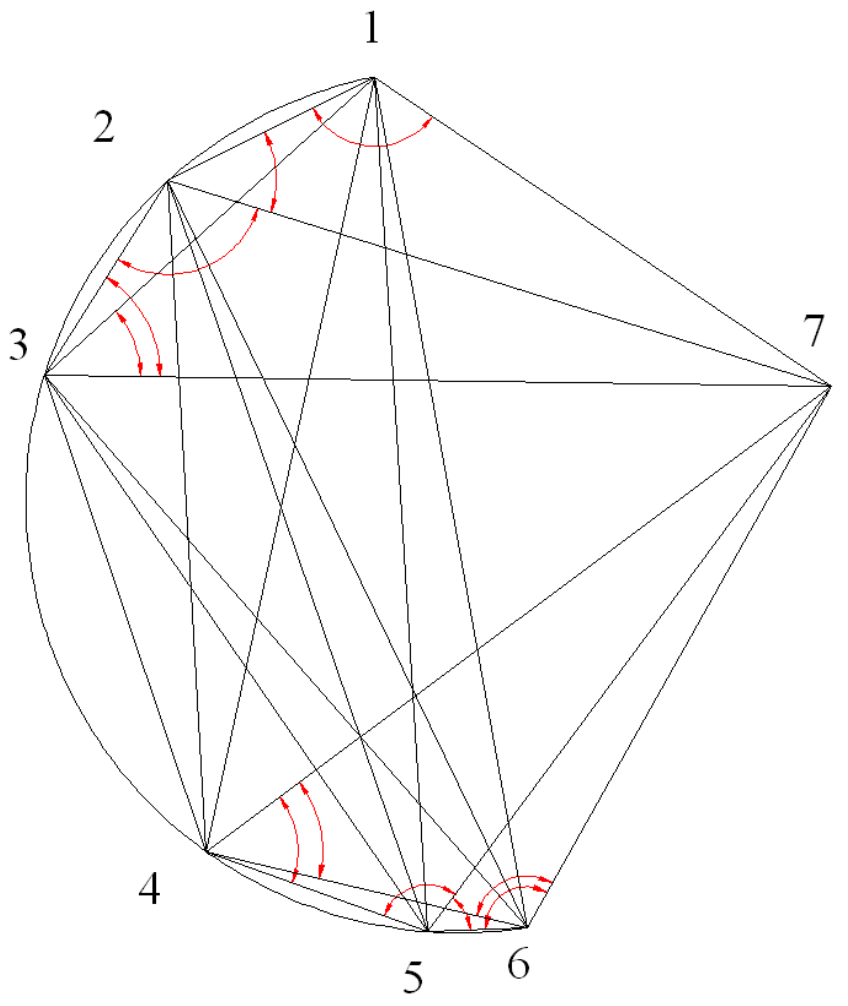

Fig. 3. Angles (red) not suitable for calibration

Angular accuracy determination is a costly task and not every laboratory can afford purchasing the equipment for realisation of such task. Calibration laboratory of Institute of Geodesy is working in this direction but until the instruments for this purpose are under the development and testing the Calibration laboratory is using the test field. Determining the accuracy of angle measurement for a total station or theodolite is not a simple task, especially when the results should be free from atmospheric effects and sighting errors.

Six pillars built in a line and seventh aside created 15 possible triangles with consequence of total of 45 interior or 45 exterior different angles. The angle values of triangle 1-6-7 were determined after multiple observations with Leica TC2003 total station $\left(0.15\right.$ mgon $\left.\left(0.5^{\prime \prime}\right) / 1 \mathrm{~mm}+1 \mathrm{ppm}\right)$.

Kyviskes calibration test field can be used to calibrate angles. Angle values can be obtained from baseline lengths using law of cosines $(1,2)$ :

$$
\begin{aligned}
& a^{2}=b^{2}+c^{2}-2 \cdot b \cdot c \cdot \cos \alpha \\
& \alpha=\arccos \left(\frac{b^{2}+c^{2}-a^{2}}{2 \cdot b \cdot c}\right)
\end{aligned}
$$

Using formula derived from law of cosines all possible 45 interior angles were computed. They vary from $0^{\circ} 46^{\prime} 48^{\prime \prime}$ to $139^{\circ} 46^{\prime} 48^{\prime \prime}$ (Fig. 2).

Triangle 1-6-7 angles were measured by Leica TC2300 and computed from distances measured by Kern Mekometer ME5000 EDM instrument. These results are compared in a Table 1:

Table 1. Comparison of computed from distances and observed angles

\begin{tabular}{llll}
\hline Angle of test field & $\begin{array}{l}\text { Angles observed by } \\
\text { Leica TC2300 }\end{array}$ & $\begin{array}{l}\text { Angles computed from } \\
\text { Law of cosines }\end{array}$ & $\begin{array}{l}\text { Difference (observed } \\
\text { - computed) }\end{array}$ \\
\hline $6-7-1$ & $94^{\circ} 48^{\prime} 47^{\prime \prime}$ & $94^{\circ} 48^{\prime} 46^{\prime \prime}$ & $+1^{\prime \prime}$ \\
$7-1-6$ & $45^{\circ} 44^{\prime} 55^{\prime \prime}$ & $45^{\circ} 44^{\prime} 54^{\prime \prime}$ & $+1^{\prime \prime}$ \\
$1-6-7$ & $39^{\circ} 26^{\prime} 18^{\prime \prime}$ & $39^{\circ} 26^{\prime} 19^{\prime \prime}$ & $-1^{\prime \prime}$ \\
\hline
\end{tabular}

By knowing extended uncertainties of baseline lengths we can compute expected uncertainties of computed angles values using formula (3): 


$$
u_{\alpha}^{2}=\frac{\rho^{2} u_{s}^{2}\left[\left(\frac{a}{2}\right)^{2}+(b-c \cdot \cos \alpha)^{2}+(c-b \cdot \cos \alpha)^{2}\right]}{(b \cdot c \cdot \cos \alpha)^{2}}
$$

The uncertainties of all possible triangle sides at Kyviskes test field do not exceed $0.9 \mathrm{~mm}$. The $u_{s}$ value equal to $\pm 1 \mathrm{~mm}$ was used to compute uncertainties for all possible 45 angles. The results show that most of angles errors are bellow $\pm 0,4 "$.

We list the angles (11 in total) with uncertainties exceeding $\pm 1^{\prime \prime}:$ 7-6-4, 7-6-5, 7-5-6, 7-5-4, 7-4-6, 7-4-5, 7-3-2, 7-3-1, 7-2-3, 7-2-1 and 7-1-2 (their graphical visualisation in Fig. 3).

The obtained results let us conclude that the rest of possible angles at the test field can be used for angular calibration with uncertainty bellow \pm 1 ".

Angles computed from lengths of the baselines are within observed angles expanded uncertainty $(\mathrm{u}= \pm 1 " \mathrm{k}=2 ; 95 \%$ confidence interval). We could say that baselines $(840 \div 1320 \mathrm{~m})$ calibration results (with expanded uncertainty $\mathrm{u}= \pm 1 \mathrm{~mm}$; $\mathrm{k}=2 ; 95 \%$ confidence interval) are sufficient to derive angles from baseline lengths.

\section{Baseline lengths variation}

Analysis of 4 observation cycles of Kyviskes Calibration Baseline was done. Air temperatures of every measurement cycle were averaged and determined baseline lengths were compared. Temperature variation between measurement cycles in 1996, 2001, 2007 and 2008 has reached up to $21^{\circ} \mathrm{C}$. The baseline length variation depending on the air temperature is more than obvious (Fig. 4).
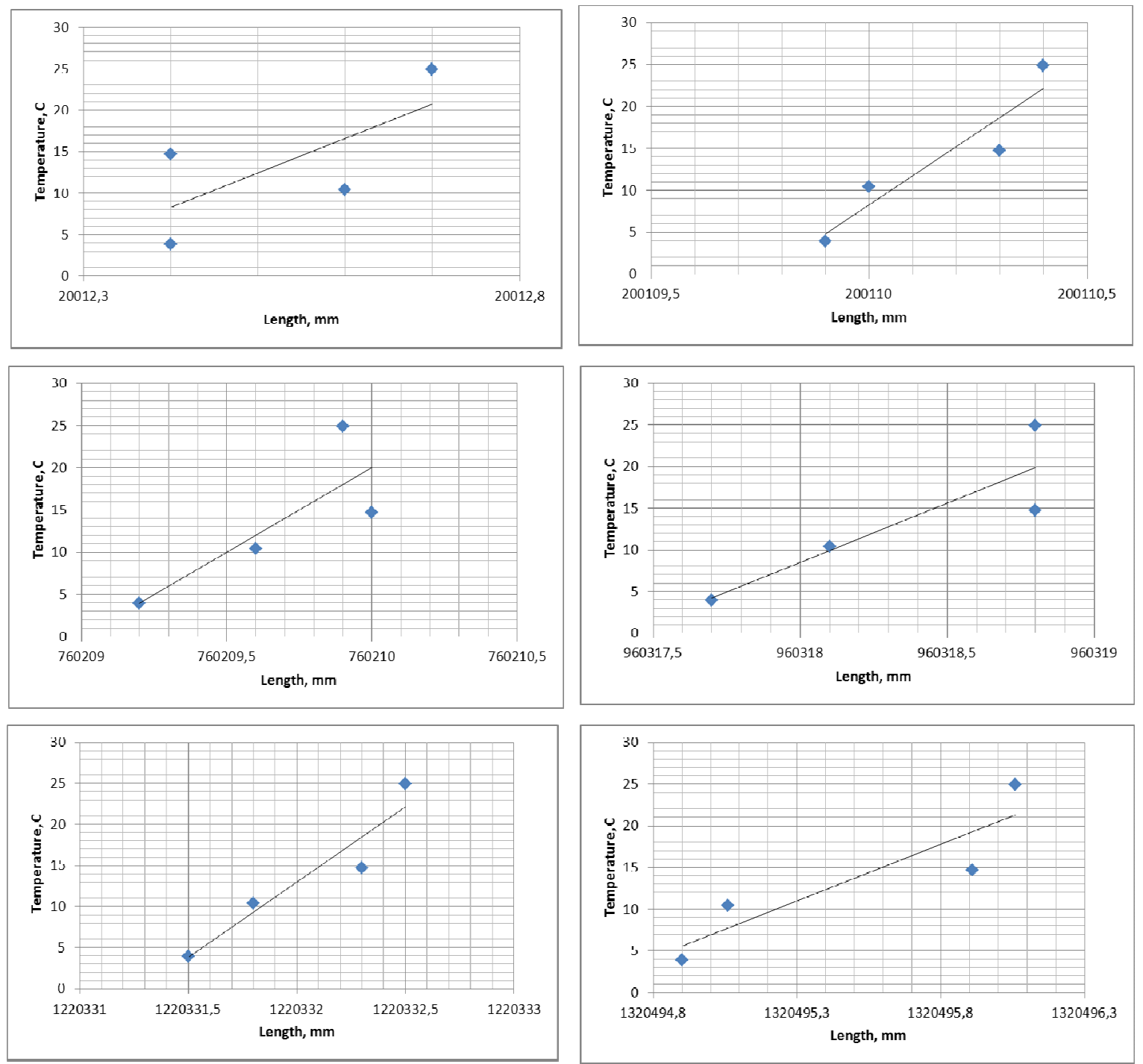

Fig. 4. Baseline length variation due to temperature changes

Correlation coefficients computed for separate baselines are listed in Table 2. 
Table 2. Correlation coefficients for separate baselines

\begin{tabular}{ccc}
\hline Length, $\mathrm{m}$ & Baseline & Correlation coefficient \\
\hline 20 & $5-6$ & 0,71 \\
200 & $4-6$ & 0,94 \\
760 & $3-4$ & 0,82 \\
960 & $3-6$ & 0,88 \\
1220 & $2-6$ & 0,95 \\
1320 & $1-6$ & 0,90 \\
\hline
\end{tabular}

Accuracy of high precision EDM (Mekometer 5000) is about $0.2 \mathrm{~mm}+0.2 \mathrm{ppm}$. A error of $1{ }^{\circ} \mathrm{C}$ in the air temperature causes about 1 PPM error in a light wave measurement. That is $1 \mathrm{~mm}$ on $1 \mathrm{~km}$ baseline. Distance determination accuracy is very temperature sensitive.

Figures clearly show the correlation. However, we think it is difficult to explain this with thermal expansion of the baseline. The recommended formulas for refraction correction are reliable. What remains, is the uncertainty of temperature measurements. Even if we have precise calibrated psychrometers, especially in unfavorable (sunny) weather conditions the uncertainty of temperature observations is much larger than the uncertainty of the temperature measurement instruments.

If we measure too high temperatures (than temperature is), we get too long baseline lengths; this could be the most probable reason for the correlation shown above. Psychrometers under parasols "run too hot" in sunny weather conditions, compared with the "true" temperatures. Anyway it is not completely cleared out the correlation between measured temperature and determined baseline because measurements during 2001 and 2008 were more cloudy than sunny.

In addition to different temperatures, comparisons between sunny and cloudy measurement conditions would be interesting, especially in open surroundings such as Kyviskes. At Kyviskes, we think the estimation of total expanded uncertainty sufficiently includes the uncertainty due to varying weather conditions, and produces compatible results. A more thoroughful analysis may reveal dependence on temperature as presented in this report. Probably the influence is not that simple to model. Finnish colleagues from FGI in their baseline calibrations within the EMRP SIB60 project in 2014 will attempt to determine vertical and horizontal temperature gradients and uncertainties due to them in new ways.

\section{Conclusions}

Magnification of the telescope and refraction are the serious problems. To get close to maximal accuracy sighting should be done not worse than $5 \mathrm{~mm}$ for the longest sides. And that is a problematic issue in the distance of $1 \mathrm{~km}$.

Kyviskes calibration baseline accuracy is sufficient to derive angles from baseline lengths and to use them for calibration of the most geodetic instruments used for angles measurement.

Calibration baseline thermal variation presented here is an interesting example but must be researched in the future to make some clear conclusions.

\section{Referemces}

[1] Jokela, J.; Petroškevičius, P.; Tulevičius, V. 1999. Kyviškès Calibration Baseline. Reports of the FGI, 99:3, p 15.

[2] Pollinger, F.; Meyer, T.; Beyer, J.; Doloca, N.R.; Schellin, W.; Niemeier, W.; Jokela, J.; Hakli, P.; Abou-Zeid, A.; Meiners-Hagen, K. 2012. The upgraded PTB $600 \mathrm{~m}$ baseline: a high-accuracy reference for the calibration and the development of long distance measurement devices, Meas. Sci. Technol. 23(2012) 094018: 11. Online at stacks.iop.org/MST/23/094018.

[3] Buga, A.; Jokela, J.; Putrimas, R.; Zygmantiene, E. 2011. Traceability, stability and use of the Kyviškès calibration baseline - the first 10 years, in D. Cygas, and K. D. Froehner (Eds.). The $8^{\text {th }}$ International Conference Environmental Engineering, Selected Papers 3: 1301-1305. Vilnius, Lithuania, May 19-20, 2011.

[4] Buga, A.; Jokela, J.; Putrimas, R. 2008. Traceability, stability and use of the Kyviškès calibration baseline - the first 10 years, in D. Cygas and K. D. Froehner (Eds.). The $7^{\text {th }}$ International Conference Environmental Engineering, Selected Papers, 3: 1274-1280. Vilnius, Lithuania, May 22-23, 2008 .

[5] Jokela, J.; Hakli, P.; Ahola, J.; Buga, A.; Putrimas, R. 2009. On traceability of long distances, in Proceedings of XIX IMEKO World Congress, Fundamental and Applied Metrology, September 6-11, 2009, Lisbon, Portugal, 1882-1887.

[6] Koivula, H.; Hakli, P.; Jokela, J.; Buga, A.; Putrimas, R. 2012. GPS Metrology: Bringing Traceable Scale to a Local Crustal Deformation GPS Network, Geodesy for Planet Earth, International Association of Geodesy Symposia 136: 105-112. http://dx.doi.org/10.1007/978-3-642-20338-1_13 